\title{
Corporeal Dimensions of Gender Violence: Ladina's Self and Body in Eastern Guatemala
}

\author{
Cecilia Menjívar, Arizona State University
}

\begin{abstract}
Based on 30 in-depth interviews with Ladina women and field work conducted in a rural town in eastern Guatemala, I examine the physical expressions that violence can take on the women's bodies, such as common physical ailments that result from emotional distress as well as sicknesses that are caused directly by the conditions in which they live. A central theme in the discussion is the embodiment of violence as it is expressed in the control of the women's body in the social milieu, such as the control of their socializing and visiting. I use a sociologically- and anthropologically-informed lens to situate corporeal questions within structures of social inequalities and human suffering and, thus, this examination contributes to debates about the relationship between body and society, macro and micro processes in the social world, as well as explorations between the women's lives and their rights. As such, this examination permits to unveil embedded structures of violence that assault the women's dignity and provoke suffering, as well as those instances in which gender solidarity is created. This examination allows us to explore implications for gender-based social justice.
\end{abstract}

Sutton (2005) notes that the body bridges the personal and the political, macro processes and micro interactions and thus connects women's bodies to extra-local, and even global, realms. Within social science theory there have been multiple approaches to examine bodily themes and questions surrounding the body, from postmodernist to post-structuralist currents (see Williams, 1999). In an excellent special issue on the embodiment of violence, Green (1998) calls for attention to concrete manifestations of suffering in theorizing about suffering and the body, to examine explicit manifestations of how violence and suffering are embodied, as violence inscribes the body with message and significance. In this article I discuss concrete corporeal manifestations of different forms of violence on ladina women in eastern Guatemala. Heeding Green's (1998) call, I use a sociologically- and anthropologically-informed approach that is substantively more grounded. This lens situates corporeal questions within structures of social inequalities and human suffering and, thus, contributes to debates about the relationship between body and society. Thus, in contrast to examining issues of representation or sexuality, I follow Farmer (2004) and other critical anthropologists and social scientists writing from Latin American (e.g., Torres-Rivas, 1998; Martín-Baró, 1991) to focus on concrete expressions of social suffering, on how multiple forms of violence and macro forces coalesce and result in social suffering for women that becomes normalized and part of the social order.

Physical expressions that injustices can take in the women's bodies include common physical ailments that result from emotional distress as well as sicknesses that are caused directly by the conditions in which the women live. Social injustices are transformed into expressions of 
violence because they lead to suffering. There is another dimension of how the embodiment of violence is expressed, such as the control of the body in the social milieu, including the control of women's socializing and visiting. An examination of both, the physical and social dimensions of violence on the body brings to the fore the invisible, yet pervasive effects of gender inequalities that make possible women's domination that are manifested even in the most intimate spheres of the women's lives. This examination makes evident forms of inflicting pain and harm that are not confined to those expressed in a direct physical manner but that in the end produce similar results, such as fear, pain, and suffering. The expressions to which I call attention also encompass mental and emotional forms of inflicting pain (see Walter, 1969). This focus also helps to clarify, in Bourgois's (2004) conceptualization, the chains of causality that link structural, political and symbolic violence in the production of everyday violence that buttresses unequal power relations and distorts social relations. As such, I also highlight key links to structural violence (Torres-Rivas, 1998) and to symbolic violence (Bourdieu, 19961997) as all these forms of violence combine in the women's lives and affect one another. I do not treat each of these forms of violence separately because that is not how they appear in the women's lives. Indeed, a better understanding of the links among the individual, the social and the political becomes possible when all these lenses are superimposed to examine women's lives.

This examination fits well with efforts to make women's experiences of gender inequality relevant for discussions of social justice. As Okin (1989) notes, it is not only the differentiation between women and men that is relevant for discussions of justice, but the domination of women by men being natural. Thus, I underscore the normalization of this domination and examine it in a personal, intimate sphere of Guatemalan women's lives - the more immediate, physical sphere of body ailments, as well as the social arena of socializing and control of movement. In line with arguments that call attention to how gender inequality in different areas of life, including work and the family, contribute to women's vulnerability, my examination underlines how gender role expectations of behavior reinforce gender inequalities and create pain and suffering for women. This approach draws attention to injustices in the lives of women that are made possible by unequal treatment and gender ideologies that normalize discrimination and vulnerability. In doing so, this analysis contributes to unearth sources of injustice and suffering for women that derive from male domination and ideologies that are so entrenched in this social milieu as to appear part of the "culture." As such, this examination brings to light normalized and routinized forms of violence that are often left unquestioned and some scholars even take them as part of "culture" and thus not as a basis for inquiry. ${ }^{1}$ Deeply entrenched and institutionalized gender differences have violent effects and consequences for the lives of women, some more obviously related to direct physical violence than others.

The focus is on non-indigenous, ladina women who live away from the Altiplano, where more direct and brutal forms of violence (many linked to the 30-year old bloody political conflict in the country) did not take place. Women in western Guatemala, mostly indigenous, have received the attention of scholars (and with good reason) who are interested in unearthing the brutality of state terror and its gendered expressions in Guatemala (see Green, 1999). My discussion builds on this previous research among Mayas to render a depiction of the broad reach of violence, including those instances that are so common place as to become invisible. An examination of

${ }^{1}$ I thank one of the anonymous reviewers for this observation. 
the multiple forms of violence in the lives of women in eastern Guatemala, who are nonindigenous and lived away from the zones where direct political terror was "a way of life" (Green, 1999), exposes the deep and broad consequences of living in a society engulfed in violence, where the population was brutalized and life became fragile and cheap, thus depicting the "long arm of violence" (Menjívar, 2008). Importantly, in pointing to the violence in women's lives I do not seek to pathologize them or to portray them solely in abject gender subordination. These women's lives are much more complex; in their moments of suffering they often turn to others, often other women, for comfort and solace, which opens spaces for opposition and permits a form of sociality that can engender collective responses. It is for this reason that in my presentation in this article I intersperse these instances of comfort with narratives of suffering. However, it is my project to focus the analytical gaze on the violence and suffering so as to retrieve them from the normality of the women's lives.

In the following sections I present a two-part discussion that highlights the embodiment of gender injustices. The first focuses on the physical suffering produced on the body and the second focuses on the hidden injuries generated as a result of control of the body's movement. Together they evince the normalized, naturalized practices that produce suffering in the women's lives. Before I turn to that discussion I will present a brief note about the empirical observations on which my discussion is based.

\section{Methods and Data}

Observations come from thirty in-depth interviews and field work I conducted among ladina women in eastern Guatemala between late 1994 and 2000 in a town I call San Alejo. ${ }^{2}$ During my initial visits and conversations I did not ask the women questions about violence, as the objective of the project was to study how women's informal networks help them deal with pregnancyrelated health care and with their children's illnesses. However, in an inductive (and emic) fashion, this topic evolved from my conversations and observations during fieldwork, as it was the women's own words that guided my attention to this aspect of their lives. For this project I also conducted field work among indigenous in the Altiplano, among whom I had expected to hear instances of violence (which I did). However, I had not anticipated that ladinas would bring up violence (in its different forms) in our conversations as well. The comparative analytical angle between the two sites helped me to discern the violence in the ladinas' lives. In addition to the interviews and follow up conversations, I talked with the women's friends, neighbors, and family members, and met with community leaders and workers, including health care workers, Catholic priests, and evangelical pastors, who complemented greatly my informants' own stories. My starting points to access the women in both sites were the local health posts, which gave me access to a wide range of social positions for the women, including class and age variation. Even though the focus in both sites was on the women's lives, I also spoke informally with men during the course of the fieldwork, but these conversations were mostly restricted to when women were present.

\footnotetext{
${ }^{2}$ All the women's names (and the town's) are pseudonyms.
} 
The ladinas in this study come from different socio-economic and educational backgrounds. Their educational level ranged from 0 years to high school; three were teachers and one was an accountant. Their ages ranged from 20 to 51 years. Eleven were formally married, three were widows and the rest were in consensual unions. Those who mentioned earning an income outside the home worked as teachers, street vendors, comadronas (midwives), store clerks, domestics; one worked seasonally as a tomato picker; one made cusha (clandestine liquor for sale); and another was a photographer. There were a couple of former college students.

\section{Health and the Somatization of Social Suffering}

The multiple forms of violence in the lives of the women I met in San Alejo were often embodied in illness (see also Green, 1998-1999). The overwhelming majority of the women with whom I spoke had some form of ailment about which they wanted to talk. Sometimes such complaints appeared to be of a physical nature, whereas at other times they seemed to be of psychological character, but in reality the two were so closely linked that it was difficult to categorize them simply as one or the other. Moreover, as Green (1998, p.5) aptly notes, "to categorize suffering simply as a manifestation of a clinical syndrome or as a culture-bound construct of reality dehistoricizes and dehumanizes the women's experiences." Thus, I link the first to aspects of health and health treatments that illustrate the physical manifestations of social suffering resulting from intertwined forms of violence. These include the consequences of unequal access to treatment and medicines, and the naturalized view that the health of others in the family comes before the women's own health. The second dimension reveals embodied manifestations of distress, including headaches, stomachaches, and such "folk" ailments as nervios and pena, conditions that at times may appear to be simply "psychological" or "part of the culture" but that upon close examination reflect the deeply entrenched violence and gender injustice in the women's lives. These two dimensions illustrate how structures of violence translate into everyday suffering and become embodied and routinized and, in Bourdieu's term, "misrecognized," that is, they express the somatization of socially instituted gender differences (Bourdieu, 1996-1997). Misrecognition, Fraser (2007) notes, is fundamental to gender inequality.

Guatemala is one of the worst performers in terms of health care outcomes in Latin America; it has one of the highest infant mortality rates and one of the lowest life expectancies at birth (Gragnolati \& Marini, 2003). Although supply-and demand-side constraints play a role, it has been found that supply plays a more central role in rural areas (Gragnolati \& Marini, 2003). The total expenditure on health as a percentage of the GDP in 2003 was 5.4 percent, and health expenditure represented 15.3 of the total government expenditure (World Health Organization, [WHO], 2006). There are 0.9 physicians and 4 nurses per 1,000 population and 5 hospital beds per 10,000 inhabitants (WHO, 2006). And overall, public health spending benefits disproportionately the highest quintiles of the income distribution of the population (Gragnolati \& Marini, 2003). In a study that examines access to health care in rural Guatemala (Goldman, Pebley \& Gragnolati, 2002), poverty emerged as a serious constraint on a family's choices about how to treat children's illnesses, and the availability of modern health facilities within a community - both government-sponsored facilities and private doctors - had a substantial impact on the type of providers sought to treat children's illnesses. And although research has shown 
that Guatemalans often resort to multiple sources and simultaneous use of home remedies, curanderos, herbalists, midwives, pharmacists, physicians, public and private health clinics and hospitals (Cosminsky \& Scrimshaw, 1980), recent research notes that modern medical care plays a central role in the treatment of infectious illness in rural Guatemala, with visits to pharmacists, doctors and the staff at government health facilities occurring much more frequently than visits to curers and other traditional practitioners (Goldman \& Heuveline, 2000). Within this overall scenario, social position, dictated by social class, ethnicity, and gender, shapes critically who ultimately gets medical treatment and who does not; indigenous groups, particularly poor indigenous women, fare even worse than the rest of the population.

A lack of access to health care based on class position and ethnicity is often compounded for women by the naturalized ideology that they put the health of others before their own. The embodiment of structural, symbolic, and everyday forms of violence in San Alejo is often expressed in malnutrition and its multiple manifestations. To be sure, malnutrition is an expression of structural violence that affects poor men as well, and poor ladinos and Maya men also suffer from lack of access to good quality medical care. However, how such lack of access is perceived and "naturalized" differs for men and women, an expression of the socialization of gender differences (and injustices) itself. Thus, using a different analytical lens, observations that I classify as forms of violence can be easily interpreted as exemplifying the suffering mother in Latin America, a representation that is often uncritically attributed to "cultural" dictates and linked to the highly contested term - "marianismo." Viewed through the analytical lens I use here, leaving reproductive and personal decisions to their partners even when the woman's life is in danger, putting the health of others before their own, and the normalization of taking the last place in the family to get treatment-practices that are so routine and commonplace in San Alejo - result from a combination of gender and gendered, symbolic, and structural violence.

The women with whom I spoke in San Alejo often mentioned "debilidad," or weakness, as an illness that affected their partners, children and themselves. Women sometimes would buy pills or tonics over the counter at a pharmacy, from vendors on market day, or the physician at the local health post would prescribe something for them to alleviate their "debilidad." For instance, Mirna, a 28 year old and mother of 5 children, often talked about what it is like for her and her family to live lacking what she considered important components of their daily diet. "Sometimes my mother comes by to see if I have a little bit of coffee left over because she gets headaches if she doesn't drink coffee every day. And me too, if I don't have a cup of coffee in the morning and at night, I have a terrible headache the next day. The thing is that we don't often have enough [money] to drink coffee everyday because we need that money so that the children can eat. Also, my husband needs to eat so that he can work. So then [laughing] it's me, I am the one who often wakes up with a headache." A health post worker told me that she often hears about such headaches from women, and explained that these are not the result of not having had a cup of coffee, but are serious cases of malnutrition that result from the women's "descuido" (or disregard) for their own health. Even though the health care worker linked the headaches to malnutrition and lack of access to food, she misdirected the root of the problem to the women themselves and their "fault" and away from the structures of inequality (and specifically gender inequality) that lead to the these consequences of malnutrition.

Susana's is another case that brings to the fore how different forms of violence coalesce in the women's bodies. She was 26 years old when we first met and had quit school midway through the second grade. She was the mother of four children (a fifth had died as a newborn); the 
following year I saw her pregnant for the sixth time (she eventually had a miscarriage). As other women also mentioned, Susana pointed out that they often ran out of money to buy her own medicine, particularly when others in the family were ill or had other necessities that were considered to be urgent. However, she said that her husband had something to do with their ill health. She suffered interpersonal violence in the home, physical and psychological, and in our conversations articulated that this was the reason for her poor health. The owner of a nearby pharmacy knows of her situation and often gives her medicine on credit or sometimes even for free, particularly when it is for the children. In Susana's words, "The owner of the pharmacy knows me; she knows my husband and our situation. She knows that my husband takes money from food and spends it in alcohol. The other day I was supposed to buy my pills because this headache leaves me unable to do anything. But he [the husband] took the money and went to get drunk, maybe with women too...who knows...who cares. I went to the pharmacy and she [the owner] gave me 3 pills, so that at least I could go to sleep. She has mercy on me." Although Susana had apparently internalized the structural and gender violence that contributed to her own dehumanization, in her moments of suffering she could turn to the owner of the pharmacy to temporarily alleviate her pain. This is what I noted earlier; women's lives do not constitute only circles of violence or social pathology; they are complicated and at times even contradictory. My task is to expose systematic patterns that are neither natural nor necessary.

Like Susana, other women also mentioned people "having mercy" on them; however, such attitude from others depended on many issues, including the women's reputation. A striking case is that of Leticia. I met her one afternoon in the dark, damp, one-room structure with dirt floor that she shared with her two young daughters. It took a few minutes for my eyes to get used to the darkness of the room, and then I began to discern Leticia's emaciated facial features. She was 27 years old and had never attended school. Eventually she died of complications from HIV/AIDS two and a half years after her husband also died from the same causes. According to people who knew her, she "left this world very sad; she worried so much about her girls because she knew they would be left orphans. Her last three months of life were so sad for her that she even lost her mind a little." She knew she was dying and that her girls would be separated, as neither set of the grandparents could take care of both. During Leticia's last year of life no one would mention the name of her illness but everyone seemed to know what ailed her. Some people would "take pity" and help her, while others tried to avoid her. However, in Leticia's eyes, those who helped her did so because she was a single mother and a widow, and most of all, respectable. In her words, "Because people see me alone, that I'm responsible for everything in the home, so people help me. They allow me to pick tomatoes, to sell them, and that's help. Sometimes I would like to go to visit my family, but that costs Q. 10 for the bus fare and it's difficult for me to save that. Once in a while people help me with that too." But not everyone "took pity" on Leticia. I also heard from her sister and a health post worker that there were people who did not want anything to do with her and had been, in fact, cruel to her. Such attitudes are related to symbolic violence that persons infected with HIV/AIDS experience (see Smith, Lucas \& Larkin, 1999). However, as I discuss in a later section, a woman's image of propriety exacerbated the effects that structural violence could have. Her image in the eyes of others was key in accessing resources, as a good reputation would likely garner benefits, regardless of the women's position. This is related to normative expectations of women's behavior that can constrain women's lives to the point of suffering and pain. 


\section{Nervios, Headaches, and the Everyday Embodiment of Distress}

Nervios ("nerves") is one of those "folk" ailments, a popular label that refers to multiple symptoms, more likely associated with a loss of emotional control, which some researchers have linked to cultural, demographic, environmental, and personality factors. In their study of Puerto Ricans in Puerto Rico and in New York, Guarnaccia, Lewis-Fernandez, and Rivera (2003) argue that there are different categories and experiences of nervios and that an examination of these multiple categories provides insights into how suffering is experienced and expressed, pointing to different social sources of distress. Other researchers have noted that nervios is a syndrome of brief duration seen primarily in Spanish-speaking people of the Caribbean (Oquendo, Howard \& Martinez, 1992) and, thus, they note that it as a cultural-specific syndrome. Perhaps there is a relationship between geographical location (e.g. Latin America and the Caribbean) and nervios. However, from my analytical angle, rather than endorsing the notion that nervios has roots in a presumed common culture, I would argue that nervios is related to the high levels of inequality in the region, which are the highest in the world. And nervios is a condition that usually ails women. Thus, in this discussion I elaborate on the links between nervios and the multiple forms of violence in which the Guatemalan women in this study live. Naturally, situating this phenomenon, as well as headaches and other embodiments of suffering, within a social and structural framework that underscores the injuries of inequality, necessitates a shift away from individualistic and "cultural" approaches to the study of these illnesses.

The eyes of Ivette, a ladina who was married to a man in the Altiplano, shifted nervously and blinked constantly when we talked even as she kept on reiterating what a good life she had. She later confessed that her nervios made her gastritis flare up, and needed to take Maalox regularly because she was almost never without pain. And Isabel, a 41-year old mother of 2 girls, told me that a year before we met her nervios were simply "killing her." "I was very thin, like this (showing her pinky finger); I didn't want to eat anything. People gave me thousands of recommendations, of advice, 'here, take this or that herb,' teas, injections, pills, sh, you name it. I got to a point where I didn't even care about my girls. I didn't want anyone to talk with me. It was at a time when I was suffering from a great pena (grief), and couldn't find consolation in anything. An evangelical lady started praying for me, and I started to feel better." At first I asked Isabel if her great pena had been of an economic nature, and she said it was. But months later she explained that she had been concerned about her husband and an affair he was having, which would also have financial consequences for her, she confessed, because there was the possibility that he would abandon her. Other women I met in town mentioned how much Isabel had suffered in those days because her husband would apparently parade himself with his mistress in front of the house he shared with Isabel; he would go to parties with his mistress, and did not seem to care who saw him or when. According to Isabel's neighbors, it was this humiliation that was literarily killing her. They agreed that these kinds of penas could kill anyone, as "your nervios get destroyed from thinking." A woman said that this kind of suffering, which women "always" experience, is so painful psychologically that in her view, it amounts to torture.

Symbolic, structural, and gender forms of violence are also expressed in illness that are associated with nervios, such as insomnia, high blood pressure, and headaches. Any of these symptoms may be caused by poor diet or malnutrition (themselves expressions of structural or symbolic violence), or a range of other ailments. However, in the women's own view, these were caused by situations linked to the (violent) context in which they lived. Thus, because the women 
interpreted them in this manner, they merit examination through the lens I propose here. Significantly, expressions of nervios were not confined to the women who were poor. Delfina is a case in point. A 35 year old teacher whose family and that of her husband are landowners and quite well off, Delfina was not immune to these ailments. Sitting in an elegant living room with chandeliers and ornate and expensive furniture, she said that she often felt that her "nervous system is altered," that her "nervios are destroyed," and that she lives on the verge of a breakdown. Even though she takes medicine for her nervios, nothing helps because, she has realized, the cause of her nervios does not come from her, but from her husband. ${ }^{3}$ Her mother-inlaw and others have recommended that she go to see a neurologist in Guatemala City, and perhaps seek therapy there. But she cannot do this because she is in a catch 22 situation. "I can't go to get treatment in Guate because I work all the time. Well, I actually like to go to work because I forget my situation at home. And if I want to go to Guate, who's going to make my husband his meals? Who's going to take care of him? He doesn't let me go. I wish I could go because I really feel like I need to be treated by a specialist. Oh no, he doesn't let any of our servants serve him; it always has to be me. God forbid I'm not home and available to serve him his meals exactly how he likes them! It turns into a scandal. Not even his mother can substitute for me. I truly live esclavizada (enslaved)." Similarly, Gloria linked her headaches and nervios to her "situation" at home and had resorted to taking medication regularly. She explained that sometimes her problems got to a point where her nervios had led to convulsions, which she had suffered since she was a little girl but have worsened in the last years of her marriage. In her words, "He won't change, so I have to do something. And what I can do is to take my medication and make sure that I see the doctor. That's all. I have to find treatment for myself if I don't want to completely lose my mind."

\section{Gossip, Image, Reputation and the Control of Movement}

Not all embodiments of gender and other forms of violence are expressed in illnesses, nervios, or physical pain. There are other dimensions that are less tangible but equally harmful; we might call these the hidden injuries of corporal inequality and they are linked to how others interpret women's behavior and attribute meaning to their actions. Thus, this aspect of violence (and injustice) to women's bodies involves meaning construction, socially-embedded but veiled injury, and the inscription of deeply unequal power relations.

One of the most powerful and efficacious forms of control in the women's lives was gossip. Taking gossip out of context or in a different discussion or situation might make this practice a "cultural" expression unrelated to violence in the way I am arguing it could be linked. However, in this milieu, where other forms of suffering act on one another, gossip acquires the form of violence because it becomes a weapon of social control and a source of humiliation, pain, and affliction in the women's lives. The women I met worried about gossip and how it could hurt their reputation as well as the consequences it might have for their lives, including abandonment or diminished support and decreased opportunities to find (and keep) a partner.

\footnotetext{
${ }^{3}$ Delfina, like the health care worker I mentioned earlier, attributed direct culpability to an individual even when the roots of the situations they pinpointed lied in structures away from individuals.
} 
Regardless of their social standing, the women were extremely careful in conducting themselves so as to not call negative attention to themselves and not to lead anyone to suspect them of "misbehaving" either in the streets or at home. As the Sullk'atas in Bolivia in Van Vleet's (2003) study, the women in San Alejo carried out their daily lives constantly aware of the talk and attention of others, which conditioned their actions, words, postures, and movements. Gossip, as it was explained to me more than once in San Alejo, can destroy women's lives. It is in this light that I discuss the place of gossip in this study.

Gossip defines power relations; talking (as well as keeping silent) about others disciplines, manages, and creates categories of virtue and deviance (Foucault, 1978). Thus, gossip permeates formal spheres of social control and as such it becomes conversation that shapes reputations (Merry, 1984; Haviland, 1977). ${ }^{4}$ In this manner, as the women in San Alejo often implied, gossip can be a dangerous tool (Haviland, 1977); it can be used to control others by managing impressions (Goffman, 1959) about those who gossip as well as about whom people gossip (Haviland, 1977). My discussion of gossip is situated within these analytical observations, and reflects the women's views and actions around talking about others and being talked about. It highlights the women's formidable efforts to portray a positive image, their efforts to avoid a negative reputation (mostly by avoiding anything that could be misconstrued negatively), and the control of the women's physical movement. As such, it underscores the injuries of gender and symbolic violence in the form of gossip in women's lives.

For the women I met in San Alejo it was vitally important to create a positive image about themselves as mothers, wives, and daughters. They were well aware that being perceived as dutiful, virtuous, and devoted would not only command respect and admiration, but also could bring pecuniary as well as non-tangible benefits to them and their families. In other words, they were fully aware that a positive image of themselves could translate into what can be called "moral capital" and this was accomplished by adhering (or seeming to adhere) to prescribed norms regarding their behaviour. The women went through lengths to be seen in a positive light, particularly by other women, even if doing so meant sacrifices, pain, and suffering that, as several women confided, they just kept to themselves. In this context, therefore, gossip could not simply be attributed to "cultural practices." Focusing on the significance it has for the women permits to unveil its destructive consequences as a form of social control.

The destructive consequences of gossip are intimately related to the control of physical movement. Often husbands and male partners, aided by their families and friends when needed, controlled where their partners and wives could or should go, how long they had for errands or visits, who could accompany them, and could determine whether the reasons for going to a particular place were warranted. The end result was an overwhelming sense of control of physical movement that constrained women and curtailed their interactions and as such became a source of distress in their lives. As with other forms of violence, this intense form of control is normalized in the context of male protection of women. Often women would even interpret such control as an expression of the men's love. It was clear that a woman's reputation needed to be protected and one way to do so was to control their movements. This translated into forms of anguish, as women

\footnotetext{
${ }^{4}$ Importantly, gossip also has been characterized as a tool to resist the control of the more powerful, as a "weapon of the weak" (see Scott, 1985).
} 
endured completely unwanted long periods of separation from friends, co-workers, and loved ones, and ultimately served much more to protect the men's reputations and less the women's safety.

Silvia was particularly concerned about this situation. She was 20 years old when we first met and had a toddler boy. She and her partner met while he was stationed as a guard in her hometown on the coast, but since they became a couple and she became pregnant, he decided that she should move in with his parents in his hometown. I was curious about this arrangement since in my mind it would have made more sense for Silvia to stay in her town, living with her own family and also close to him. Even if patrilocality was the norm, she explained, "Well, when we got together he said that he needed to control me more, that he didn't like to imagine where I was when I wasn't with him and I know a lot of people in my town. Since he couldn't be with me all the time because he was working, he said that I should come to live with his parents. This way I'm more controlled. It's just that he likes to control. So I always have someone watching over me. I can't even go to the corner store without asking for permission from his parents. Yes, controlled, he needs to control me like that." Living in her husband's town Silvia faced an added complication; she was originally from a coastal town and women from there had a "bad reputation" in San Alejo. And with her husband away, she hardly left the house for fear that people would talk. In her words, "If people see me going around in the street, they'll think I'm looking for men, so he [the husband] says that I should just stay home, so he doesn't have any problems with me or with his family. Sometimes I go out of the house with my sisters-in-law, but I don't go out alone because I prefer to avoid problems." In fact, Silvia almost never left the room in which she lived because she did not like to mingle much with her other sisters-in-law and the large family of in-laws, and preferred the solitude of her own room. Indeed, I came to associate Silvia with the light green walls of her room, since I rarely saw her in other parts of the house. She usually looked quiet, perhaps even sad, when she talked about her "situation." What was most distressful to her was that her partner had allowed her to visit her parents only once every eight months, when he could take her for the visit himself, even though he worked in her home town and would only come home one weekend per month. From his, and his family's, point of view, avoiding gossip about Silvia was more important for the family's reputation.

One of the most intriguing aspects of the women's explanations was not just the level of control the men exerted in their lives or how much their physical movements were constrained, but rather how normalized this aspect of their lives seemed to be. For instance, for Estrella, a 46 year old photographer who supported her entire household with her work, it was just how things were. Her current husband was about 15 years her junior and she needed to be out of the house to go take photographs at different events, which posed difficulties. She explained in a matter-of-fact manner why it was difficult for her to be "alone" when her husband was not in town. "Yes, I would very much like for my husband to be here with me, you know, it's the man that lends respect to the house. For instance, he can tell me where to go, where not to go. I can't go out at night, yes, even for work, because I don't want people to talk. And it's dangerous here now, with robberies and bad things. He has already told me that I can't go out at night. He says that he worries about me. They [husbands] think and think and they become preoccupied. I want to avoid him any headaches. As a woman, one has to obey and not create problems, right? Such is life."

For many women restrictions on physical movement left them feeling lonely, and they usually spoke of "accepting" their situation-often stated as rhetorical questions-because that is how things were. In some cases, however, the women spoke about the serious effects of these constraints in their lives, such as being restricted from going to work, completing a course of study, or even 
visiting their own parents, as in the case of Silvia, mentioned above. In such situations, the women would seem to be more aware of the downside of this form of "protection" and even though they still pointed to its normality, they would note the negative consequences it had for them. In Emilia's case her husband measured the time it took for her to get home from work and vice versa, and would get upset if she took longer for any of those trips. Sometimes she had work-related meetings in a city half an hour away, but she tried not to attend those when he was in town; luckily, she said, he worked in the United States nine months out of the year and somehow this made things easier for her. She explained, "When he isn't in town it's fine; I can attend the meetings and work in a more relaxed way. But when he is in town, I live tormented because I have to be home exactly on time. I have to leave work even if my boss gets upset at me because my husband gets very angry. Yes, when he's in town I feel really constrained, almost not alive." At work her colleagues knew about her home situation and understood that when "the husband" was in town Emilia barely said hello to anyone and rushed home as soon as she could. A co-worker told me, "She looks so bad when he's around. The moment he goes back to the States her face changes and she seems to be happy; yes she can be happy but only if he's not here (laughs hard). No, it's true, everyone knows that." In the case of Hortencia, her partner sometimes would not even allow her to finish her work. Sometimes she would take clothes to wash for other people to make a little extra money, but her partner would not allow her to do that, particularly if it involved walking around town, so she would come up with strategies to give back the clothes behind his back. Once she took advantage that he was not at home so she washed but had to give the clothes wet to her client before his return. She would do anything to earn extra money "in a decent way" but her partner would oppose anything that would require her to go out of the house more than he thought was necessary.

As in Silvia's case earlier, other women seemed more affected emotionally when the restrictions also applied to visits to their parents. Delfina, who often described her husband as simply "malo" (bad, mean), would complain about the rules her husband had imposed on her visits to her family, who lived in a town about one hour drive from San Alejo. In her words, "Well, he lets me go, but I can't ever stay there over night. Since I got married 17 years ago I've never slept outside of our house, not even at my parents' because he's so strict about that. It's the same with our daughters. He doesn't even let them get into cars with their own (male) cousins. He says to me, 'you and I know that they're cousins, but other people just see men in the car, and I don't want people to go around saying that my daughters were seen riding around with some men.' Oh, you should see how he gets. I would love to stay at least one Saturday night at my parents' but that's not possible (her intonation denoted assertion). I have to serve him his breakfast and then come to serve him lunch. One day he got upset because I wasn't home to serve him a glass of lemonade! Imagine? Another time he was looking for his black boots and couldn't find them and I wasn't home and he got angry. Can you imagine?" Delfina pointed out that her husband was old enough to find his own boots, but that he acted in this way just to control her and to determine how long she can stay when she visits her relatives. "Usually, I just go, quickly, and then have to rush home. I think my mother suffers for me, but she won't say anything because it's my husband."

Emilia was happy that her husband had changed a little since they were first married. At first he would only give her half an hour to go visit her parents, and this was never enough. "He used to control me and give me half an hour to go. So I would go in and out of my parents' house like lightening because he would go wait for me but thanks to God he is not like that anymore. My mother and even my mother-in-law talked to him because life was getting to be unbearable for me." And Gracia spoke of visits to her mother's as if they were something to hide. She explained, "You 
know, once in a while me doy mis escapaditas (I escape a little) to go and talk with my mother a little bit. But it's really not good for me because I'm always afraid. I am always busy around the house, cleaning, cooking, washing, and so I don't have time to get out. And imagine if my husband sees that nothing has been done in the house and I'm out visiting? And he doesn't like me going out just to visit. Oh God no! He has even gone to get me from my mother's house to bring me home." Thus, while the presence of other women creates spaces for sociality that complicates the descriptions of violence in the lives of women, these do not always constitute arenas for resistance.

Control of physical movement would take place even when the men were living and working in the United States. Sometimes a husband or male partner would call on the phone to express his wishes for where his partner should reside or where she could go and with whom, and often his relatives in town would enforce his decisions. For Lucía, a 42 year old teacher and mother of three young children, life had been going well since she got married. Her husband had been traveling to the United States seasonally for the previous five years and she had been able to live with her parents in her hometown all that time. But one day, out of the blue, her husband called from Connecticut to tell her that he had decided that she move to San Alejo. In her words, "He said, either you come here with me or you go to live in San Alejo. I was so surprised, I thought, why? But what could I say? I couldn't say no, right?" Apparently, her husband had gotten the idea from the compatriots with whom he lived and worked in Connecticut, who had done the same with their partners. It was hard for Lucía to move to San Alejo because she much preferred to live with her family while her husband was in the United States, but she said she had no choice. And in the case of Mercedes, a 51 year old mother of 8, her husband was in Guatemala when she was visiting her ailing father in Chicago. According to the doctors her father was in critical condition and was not expected to make it through the week, but Mercedes had promised her husband that she would be back in Guatemala sooner. So she called her brother in Guatemala City so he could intercede on her behalf and plead with her husband to allow her to stay in Chicago until her father passed. "Luckily, Beto (the husband) gave me permission to stay, but I was really nervous because he had said no before and what would keep him from saying no now?"

\section{Discussion and Conclusion}

The lens I use here allows an examination of body ailments, malnutrition, unequal access (or lack thereof) to health care, as well as the control of gossip and movement and socializing as arenas where social suffering becomes visible and recognized. Examined through other lenses these instances could be taken as indicators of inequality, perhaps gender inequality, and some could even be interpreted as part of tradition, as internally-driven and linked to culture. However, the women's words and stories and their posture, body language, and expressions as they related their experiences brought out key links to multiple structures of violence and gender injustice. As the women narrated their lives, visible forms of suffering - couched in a language of fear, pain, and distress - arising from structural, symbolic, everyday, gender and gendered violence could be discerned. In this way, the ailments, gossip, and control of movement are not simply expressions of tradition or culture; they are the embodiment of violence in their worlds, of the suffering, fear, and neglect. I simply could not dismiss the harmful consequences of control and of the deeply unequal power relations in the women's lives; even if these were not as evident as the direct physical or even political violence present in other regions of Guatemala (or in other 
contexts), they had profoundly injurious consequences for the women I came to know in San Alejo. Equally distressing was the normalization of their suffering, even in cases where the women's reflections had a hint of questioning the way things were. Unearthing suffering and violence in the women's lives is crucial because the unquestioned embeddeness of culture and the normalization of pain conceal structures that facilitate harming women in more direct, physical ways, such as in the case of the femicides that are taking place all over Guatemala. The politics of recognition are a key component of any efforts toward gender justice.

In a discussion of the somatization of socially-instituted gender differences, Bourdieu (19961997) observes that female acts of cognition are inevitably "acts of misrecognition" that make acceptance of dominance possible. For Bourdieu and Wacquant (2004) gender domination represents the paradigmatic form of symbolic violence. My focus on quotidian instances in the women's lives permits to unveil (perhaps to scratch the surface of) embedded structures of violence that assault the women's lives and provoke suffering and humiliation. And just as issues of "family justice," (Okin, 1989) including terms of divorce and domestic and family violence, have become increasingly visible, other, less obvious but equally harmful forms of gender injustice need to be pinpointed and understood. Neglect is another form of violence. 


\section{References}

Bourdieu, P. (1996-1997). The Goffman Prize Lecture: Masculine Domination Revisited. Berkeley Journal of Sociology, 41, 189-203.

Bourdieu, P. and L. Wacquant. (2004). Symbolic Violence. In N. Scheper-Hugues \& P. Bourgois (eds.), Violence in War and Peace (pp. 272-274). Malden, MA: Blackwell Publishing.

Bourgois, P. (2004). US Inner-City Apartheid: The Countours of Structural and Interpersonal Violence. In N. Scheper-Hugues \& P. Bourgois, (eds.), Violence in War and Peace (pp. 301-308). Malden, MA: Blackwell Publishing.

Cosminsky, S. \& Scrimshaw, M. (1980). Women and Health Care on a Guatemalan Plantation. Social Science and Medicine, 25 (10), 1163-1173.

Farmer, P. (2004). An Anthropology of Structural Violence. Current Anthropology, 45 (3), 305-325.

Fraser, N. (2007). Feminist Politics in the Age of Recognition: A Two-Dimentional Approach to Gender Justice. Studies in Social Justice, 1 (1), 23-35.

Foucault, M. (1978). The History of Sexuality: An Introduction, (Vol I). New York: Random House Inc.

Goffman, E. (1959). The Presentation of Self in Everyday Life. Garden City, N.Y: Doubleday.

Goldman, N., Pebley, A.R. \& Gragnolati, M. (2002). Choices about Treatment for ARI and Diarrhea in Rural Guatemala. Social Science \& Medicine, 55 (10), 1693-1712.

Goldman, N. \& Heuveline, P. (2000) Health-Seeking Behaviour for Child Illness in Guatemala. Tropical Medicine \& International Health, 5 (2), 145-155.

Gragnolati, M. \& Marini, A. (2003). Health and Poverty in Guatemala. World Bank Policy Research Working Paper No. 2966. Retrieved from: http://ssrn.com/abstract=636328

Green, L. (1999). Fear as a Way of Life: Mayan Widows in Rural Guatemala. New York: Columbia University Press.

Green, L. (1998). Lived Lives and Social Suffering: Problems and Concerns in Medical Anthropology. Medical Anthropology Quarterly, 12 (1), 3-7.

Guarnaccia, P., Lewis-Fernandez, R. \& Rivera M. M. (2003). Toward a Puerto Rican Popular Nosology: Nervios and Ataque de Nervios. Culture, Medicine and Psychiatry, 27 (3), 339-366.

Haviland, J. (1977). Gossip, Reputation and Knowledge in Zinacantan. Chicago and London: University of Chicago Press.

Martín-Baró, I. (1991b). Violence in Central America: A Social Psychological Perspective. In J. Hassett \& H. Lacey (eds.), Towards a Society that Serves Its People: The Intellectual Contributions of El Salvador's Murdered Jesuits (pp. 333-346). Washington D.C: Georgetown University Press.

Menjívar, C. (2008). Violence and Women's Lives in Eastern Guatemala: A Conceptual Framework. Latin American Research Review, 43 (3), 109-136.

Merry, S. E. (1984). Rethinking Gossip and Scandal. In D. Black (ed.) Toward a General Theory of Social Control: The Fundamentals (Vol I), (pp. 277-301). New York: Academic Press.

Okin, S. M. (1989). Justice, Gender, and the Family. New York: Basic Books.

Oquendo M., Horwath, E. \& Martinez, A. (1992). Ataques de Nervios: Proposed Diagnostic Criteria for a Culture Specific Syndrome. Culture, Medicine and Psychiatry, 16 (3), 367-376.

Scott, J. C. (1985). Weapons of the Weak: Everyday Forms of Resistance. New Haven: Yale University Press.

Smith, L. C., Lucas, K.J. \& Latkin, C. (1999). Rumor and Gossip: Social Discourse on HIV and AIDS. Anthropology \& Medicine, 6 (1), 121-131.

Sutton, B. (2005). Body Politics and Women's Consciousness in Argentina. Ph.D. Dissertation, University of Oregon. 
Torres-Rivas, E. (1998). Sobre el Terror y la Violencia Política en América Latina. In R. Papadopoulos (ed.). Violencia en una Sociedad en Transición (pp. 46-59). Programa de Naciones Unidas para el Desarrollo. San Salvador, El Salvador.

Van Vleet, K. (2003). Partial Theories: On Gossip, Envy and Ethnography in the Andes. Ethnography, 4 (4), 491-519.

Walter, E. V. (1969). Terror and Resistance: A Study of Political Violence, with Case Studies of some Primitive African Communities. New York: Oxford University Press.

Williams, S. J. (1999). Is Anybody There? Critical Realism, Chronic Illness and the Disability Debate. Sociology of Health and Illness, 21 (6), 797-819.

World Health Organization. (2006). Core Health Indicators. Retrieved from: http://www3.who.int/whosis/core/core_select.cfm 